\title{
Analisis Video Comments to Followers Ratio Tiktok Pada 5 Artis Indonesia dengan Tarif Endorse Termahal
}

\author{
I Made Arya Junitra \\ aryajunitra06@gmail.com
}

\begin{abstract}
The TikTok app is a Chinese social network and music video platform that was launched in September 2016. The app allows users to create short music videos. In Indonesia, there are 30.7 million active users, making Indonesia the country with the largest TikTok users in the world. The large number of active TikTok users in Indonesia can certainly provide opportunities for artists in Indonesia to get endorsements and this has caused these 5 artists to be named the artists who have the most expensive endorsements including: Raditya Dika, Raffi Ahmad, Luna Maya, Ayu Ting Ting, and Princess Syahrini. The purpose of this study is to calculate the credibility of the Tiktok account performance on 5 Indonesian Artists with the Most Expensive Endorse Rates. The method used for this research is quantitative exploratory method. The results of this study indicate that the artist Princess Syahrini gets the first rank and has good account performance credibility.
\end{abstract}

\begin{abstract}
ABSTRAK
Aplikasi TikTok adalah sebuah jaringan social dan platform video musik Tiongkok yang diluncurkan pada September 2016. Aplikasi tersebut memperbolehkan penggunanya untuk membuat video music dengan durasi singkat. Di Indonesia terdapat 30,7 juta pengguna yang aktif sehingga menjadikan Indonesia sebagai negara dengan pengguna TikTok terbesar di dunia. Maraknya jumlah pengguna TikTok yang aktif di Indonesia tentu dapat memberikan peluang bagi artis di Indonesia untuk mendapatkan endorsement dan ini menyebabkan 5 artis ini dinobatkan sebagai artis yang memiliki endorse termahal diantaranya: Raditya Dika, Raffi Ahmad, Luna Maya, Ayu Ting Ting, dan Princess Syahrini. Tujuan dari penelitian ini yaitu untuk menghitung kredibilitas dari performa akun Tiktok Pada 5 Artis Indonesia dengan Tarif Endorse Termahal. Metode yang digunakan untuk penelitian ini yaitu metode eksploratif kuantitatif. Hasil dari penelitian ini menunjukan bahwa artis Princess Syahrini mendapatkan peringkat pertama dan memiliki kredibilitas performa akun yang baik.
\end{abstract}

Keyword : Credibility Account TikTok ; Social Media Endorsement ; Social Media TikTok ; Video Comments to Followers Ratio ; Artis Indonesia 


\section{PENDAHULUAN}

Teknologi informasi dan komunikasi yang telah berkembang dengan pesat mampu menghantarkan manusia untuk menciptakan bentuk baru dalam cara berkomunikasi serta berinteraksi melalui media sosial. Keberadaan media sosial ini telah memberikan dampak yang signifikan di berbagai bidang seperti: sosial, ekonomi, pendidikan dan bidang lainnya. Media sosial dapat memperluas pertemanan dengan mempublikasikan kehidupan pribadi mereka kejaringan ini. Media sosial menyediakan kesempatan bagi pengguna untuk berkomentar dan berbagi informasi tak terbatas secara gratis (Ruth \& Candraningrum, 2020).

Dengan pesatnya perkembangan teknologi media sosial, telah memberikan dampak terhadap situs-situs komunikasi, dari yang awalnya hanya sekedar email dan chatting, saat ini sudah banyak jejaring media sosial yang bisa digunakan sebagai alat komunikasi. Contoh aplikasi sosial media yang memiliki banyak pengguna saat ini yaitu TikTok. TikTok merupakan aplikasi yang diluncurkan oleh perusahaan asal Tiongkok. Tiktok memungkinkan penggunanya membuat video berdurasi 15 detik yang disertai dengan musik, filter, dan beberapa fitur kreatif lainnya (Adawiyah 2020).

Di Indonesia terdapat 30,7 juta pengguna yang aktif sehingga menjadikan Indonesia sebagai negara dengan pengguna Tiktok terbesar di dunia. Maraknya jumlah pengguna Tiktok yang aktif di Indonesia tentu dapat memberikan peluang bagi pembisnis, brand, maupun lainya untuk menjadikan platform Tiktok sebagai platform social media marketing. Adapun 5 artis Indonesia dengan tarif endorse termahal di tiktok diantaranya Raditya Dika, Raffi Ahmad, Luna Maya, Ayu Ting Ting, dan Princess Syahrini. Tujuan dari penelitian ini yaitu untuk menghitung kredibilitas dari performa akun Tiktok 5 artis Indonesia dengan tarif endorse termahal. Metode yang digunakan untuk penelitian ini yaitu metode eksploratif kuantitatif. Hasil dari penelitian ini menunjukan bahwa akun Princess Syahrini mendapatkan peringkat pertama dan memiliki kredibilitas performa akun yang baik.

Penelitian ini menggunakan metode eksploratif kuantitatif, dan akan menghitung menggunakan rasio-rasio yang ada pada Tiktok. Pada penelitian (I Putu Hendika Permana \& Ni Putu Suci Meinarni, 2021) menjelaskan bahwa terdapat 17 rasio yang ada pada sosial media Tiktok dan relevan digunakan sebagai media ukur kredibilitas akun yang ada. Penelitian ini hanya berfokus untuk menghitung kredibilitas Video Comments to Followers Ratio pada Tiktok 5 artis Indonesia dengan tarif endorse termahal. Tujuan dari penelitian ini adalah mengetahui kredibilitas performa dari akun Tiktok 5 artis Indonesia dengan tarif endorse termahal menggunakan Video Comments to Followes Ratio. 


\section{TINJAUAN PUSAKA}

Media sosial merupakan salah satu dari perkembangan internet. Memiliki kamera berkualitas tinggi pada smartphone membuat banyak orang mempunyai aktivitas baru yang menyenangkan, orang akan mudahnya mengambil gambar dimanapun dan kapanpun, setelah itu diupload ke media sosial. Jenis media sosial yang biasa digunakan antara lain facebook, twitter, path dan instagram. Instagram merupakan aplikasi berbagi foto yang memungkinkan pengguna mengambil foto, menerapkan filter digital, dan membagikannya ke berbagai layanan jejaring sosial.

Menurut lembaga survei asal London, 'We Are Social', tahun 2019 Instagram berada di posisi keempat media sosial paling banyak digunakan oleh penduduk Indonesia. Seiring berkembangnya era digital, kini telah muncul platform media baru yang menyediakan dukungan dalam pembuatan video yaitu Tiktok. Menurut Sensor Tower, sebuah lembaga penyedia survei mengenai aplikasi ekonomi global asal Amerika Serikat, Tiktok berhasil menjadi aplikasi nomor 1 yang paling banyak diunduh pada tahun 2019 sebanyak 1 milliar kali di App Store dan Google Play dan berhasil meraih kepopuleran tertinggi di 6 negara dan salah satunya adalah Indonesia (Mikhael, 2019, p.5)

Aplikasi tiktok di tahun 2020 berkembang pesat dan menjadi budaya baru di Indonesia. Meskipun aplikasi tersebut sudah ada sejak tahun 2018 namun belakangan ini aplikasi tersebut banyak digandrungi oleh masyarakat berbagai usia. Pada awal munculnya aplikasi tersebut sempat diblokir oleh Kementerian Komunikasi dan Informatika dengan alasan aplikasi tersebut memberikan dampak negatif untuk anak - anak. Setelah 2 tahun berlangsung aplikasi tik tok menjadi trend dan budaya baru buat masyarakat Indonesia (Utama dan Novina, 2018).

Aplikasi TikTok tidak hanya digunakan untuk membuat konten video dengan tujuan menghibur pengguna lainnya. Aplikasi TikTok juga dapat dijadikan peluang bagi brand atau perusahaan sebagai platform social media marketing. Penelitian (Purnamasari and Tutiasri (2021) menyatakan bahwa TikTok berpengaruh positif dan signifikan terhadap minat beli atau berbelanja secara online. Sehingga dengan ini, TikTok mampu memberikan peluang yangsangat tinggi bagi perusahaan-perusahaan dalam melakukan digital marketing.

TikTok dirasakan memiliki kekuatan ataupun pengaruh dalam industri, sehingga menimbulkan kualitas akun yang menentukan strata maupun kredibilitas pemilik akun.Kredibilitas akun TikTok merupakan suatu hal yang cukup penting untuk berbagai kepentingan. Kredibilitas sebuah akun TikTok dapat diukur dari tingkat performa yang dihasilkan secara matematis. Dalam mengukur performa diperlukan skala pengukuran yang tertuang ke dalam rasio. 


\section{METODE PENELITIAN}

Penelitian ini menggunakan metode eksploratif kuantitatif untuk mengetahui kredibilitas dari performa akun Pada 5 Artis Indonesia dengan Tarif Endorse Termahal. Metode eksploratif merupakan penelitian yang memiliki tujuan untuk melakukan eksplorasi atau memperdalam pengetahuan ataupun ide-ide baru mengenai suatu hal yang baru, guna merumuskan permasalahan secara terperinci (Maryam et al., 2016).

Tujuan dari penelitian ini yaitu mengetahui nilai kredibillitas dari performa akun Pada 5 Artis Indonesia dengan Tarif Endorse Termahal. Ada beberapa langkah yang harus dilakukan dalam penelitian ini, sehingga mampu menemukan peringkat pertama akun TikTok Inilah 5 Artis Indonesia dengan Tarif Endorse Termahal yang memiliki performa terbaik. Langkah-langkah yang dilakukan pada penelitian ini, diantaranya yaitu :

\section{Melakukan Eksplorasi Pada Website Untuk Menentukan Objek yang Akan Dianalisa.}

Eksplorasi ini dilakukan pada beberapa halaman website yang menyediakan informasi mengenai objek yang akan di teliti. Setelah ekslorasi selesai dilakukan, sehingga ditemukan nama-nama artis di Indonesia yang akan dijadikan objek analisa. Setelah melakukan eksplorasi pada halaman website, maka langkah selanjutnya yaitu mencari nama akun TikTok dari masing-masing Artis Indonesia. Pastikan semua memiliki akun pada aplikasi sosial media TikTok.

\section{Menghitung Nilai Rata-Rata Variable Dari Inilah 5 Artis Indonesia dengan Tarif Endorse Termahal.}

Pada langkah ini, peneliti menghitung nilai variable video comments dan variable followers. Variabel merupakan sesuatu yang memiliki nilai bervariasi dimana nilai tersebut dapat dijadikan sebagai dasar untuk empat data yang berbeda seperti rasio, skala, ordinal, nominal dan internal (Rankuti, 2015). Untuk menghitung nilai rata-rata dari variabel video comments dan variabel video views yaitu dengan cara mengambil minimal 10 postingan kemudian di hitung sehingga menemukan nilai rata-rata dari masing-masing variabel. 


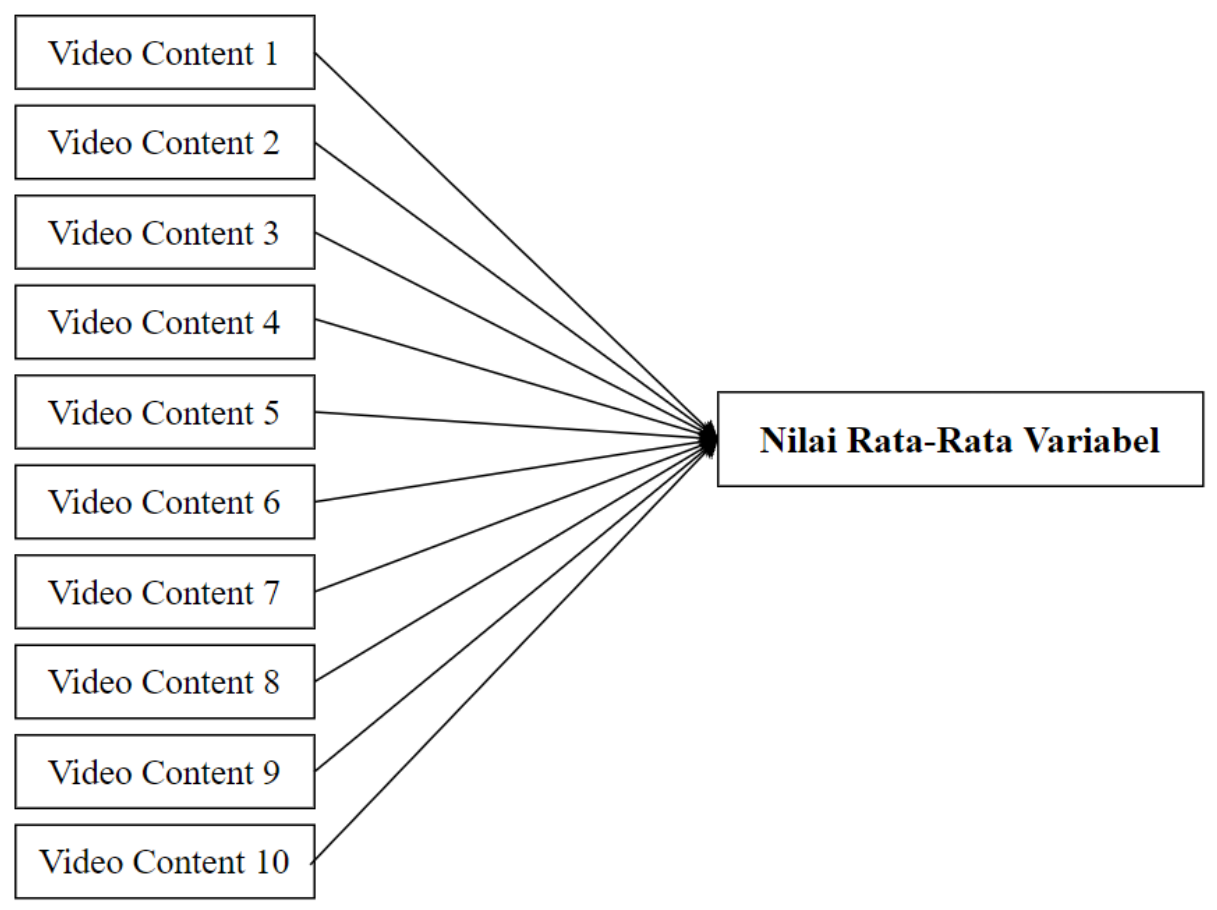

Gambar 1. Analisa Nilai Rata-Rata Variabel.

\section{Menghitung Nilai Kredibilitas Rasio}

Untuk menghitung nilai kredibilitas dari video comments to video views ratio, peneliti menggunakan cara membagi nilai variabel pertama dengan nilai variabel kedua. Jika video comments memiliki nilai 100 dan video views memiliki nilai 300, maka cara menghitungnya yaitu $100: 300=0,3$. Dengan begitu nilai dari video comments to followers ratio adalah 0,3 .

\section{Menentukan Peringkat Pada Akun TikTok}

Pada langkah terakhir yang dilakukan pada penelitian ini yaitu menentukan peringkat pada masing-masing rasio yang ada. Pada penentuan peringkat perlu melihat karakteristik dari rasio yang di teliti. Jika karakteristik rasio merupakan rendah, maka objek yang memiliki nilai terendah akan mendapatkan angka 5 dan objek yang memiliki nilai tertinggi akan mendapatkan angka 1. Namun jika rasio memiliki karakteritik tinggi maka objek yang mendapatkan nilai tinggi akan mendapatkan angka 5 dan objek yang mendapatkan nilai terendah akan mendapatkan angka 1 . Setelah mendapatkan hasil kredibilitas ratio maka dapat disimpulkan objek yang mana mendapatkan peringkat 1 sampai dengan peringkat 5 . 


\section{HASIL DAN PEMBAHASAN}

Akun Tiktok dari 5 Artis Indonesia dengan Tarif Endorse Termahal, diantaranya:

\section{Raditya Dika}

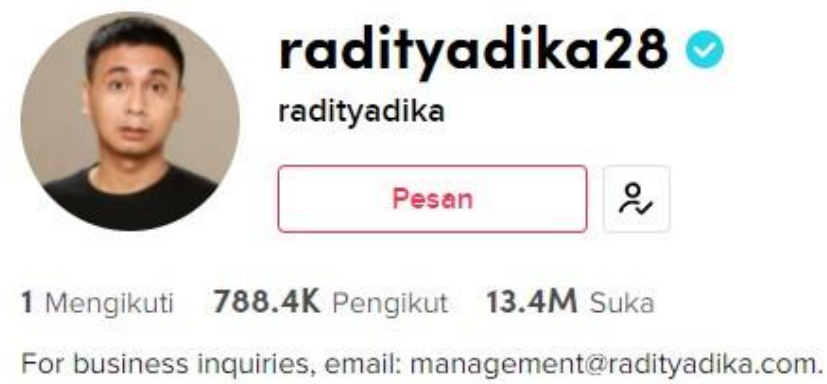

Gambar 1. Akun Tiktok Raditya Dika

Sumber: https://www.tiktok.com/@ radityadika28 (akses pada 21-10-2021)

\section{Raffi Ahmad}

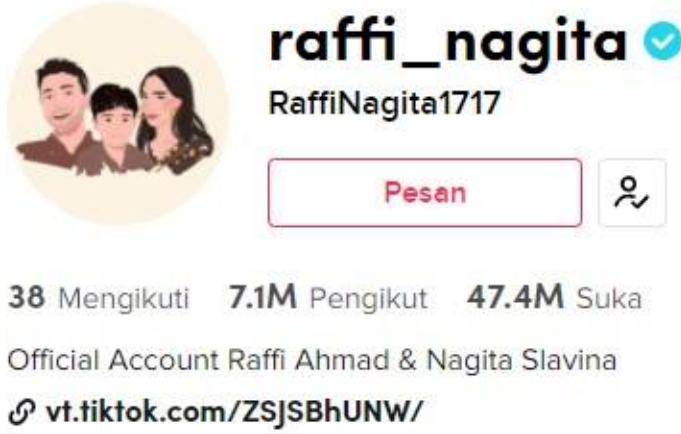

Gambar 2. Akun Tiktok Raffi Ahmad

Sumber: https://www.tiktok.com/@raffi_nagita (akses pada 21-10-2021) 


\section{Luna Maya}

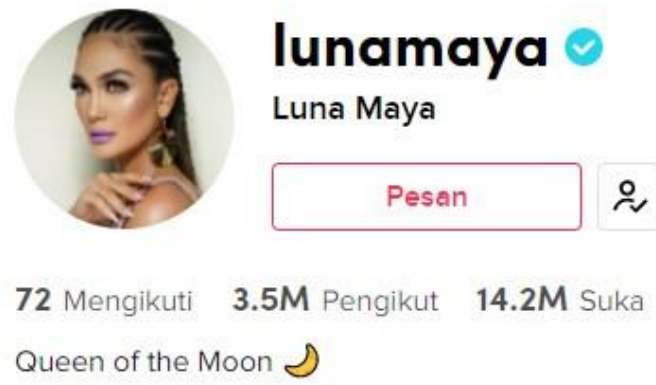

Gambar 4. Akun Tiktok Luna Maya

Sumber: https://www.tiktok.com/@lunamaya (akses pada 21-10-2021)

\section{Ayu Ting Ting}

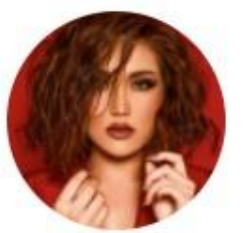

\section{ayutingting}

Ayu Ting Ting
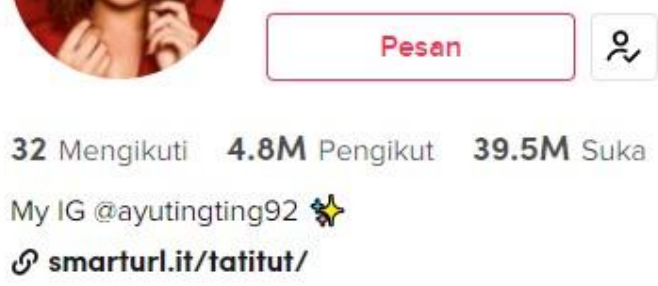

Gambar 3. Akun Tiktok Ayu Ting Ting

Sumber: https://www.tiktok.com/@ayutingting (akses pada 21-10-2021) 


\section{Princess Syahrini}

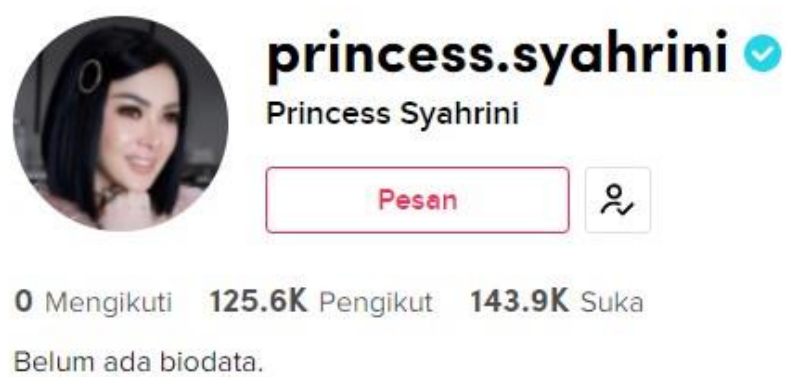

Gambar 2. Akun Tiktok Princess Syahrini

Sumber: https://www.tiktok.com/@princess.syahrini (akses pada 21-10-2021)

Dari kelima akun Tiktok Akun Tiktok dari 5 Artis Indonesia dengan Tarif Endorse Termahal, peneliti menemukan nilai dari masing-masing variabel yang ada untuk menghitung rasio Video Comments to Followers dari setiap akun. Pada akun Tiktok terdapat 7 variabel, diantaranya yaitu:

1. Likes

2. Followers

3. Following

4. Video Likes

5. Video Comments

6. Video Share

7. Video Views

Dari ketujuh variabel tersebut peneliti hanya fokus untuk menemukan hasil dari 2 variabel, yaitu:

\section{Video Comments}

2. Followers

Dari kedua variabel tersebut kemudian dianalisa sehingga menemukan nilai rata-rata dari variabel video comments dan variable followers. Untuk menghitung nilai rata-rata dari variabel video comments dan variabel video views yaitu dengan cara mengambil minimal 10 postingan kemudian di hitung sehingga menemukan nilai rata-rata dari masing-masing variabel. Berikut merupakan tabel nilai rata-rata dari masing-masing akun artis di Indonesia, yaitu: 
Tabel 1. Analisa Nilai Rata-Rata Nilai Variabel Video Comments dan Followers Akun Tiktok Raditya Dika

\begin{tabular}{|c|r|r|}
\hline No & Video Comments & Followers ratio \\
\hline 1 & 151 & 754.600 \\
\hline 2 & 1.222 & \\
\hline 3 & 52 & \\
\hline 4 & 795 & \\
\hline 5 & 235 & \\
\hline 6 & 1.222 & \\
\hline 7 & 624 & \\
\hline 8 & 1.083 & \\
\hline 9 & 4.576 & \\
\hline 10 & 6.414 & \\
\hline Total & $\mathbf{1 6 3 7}$ & \\
\hline
\end{tabular}

Sumber: Pengolah Data Excel

Tabel 2. Analisa Nilai Rata-Rata Nilai Variabel Video Comments dan Followers Akun Tiktok Raffi Ahmad

\begin{tabular}{|c|c|c|}
\hline No & Video Comments & Followers ratio \\
\hline 1 & 1.150 & 7.000 .000 \\
\hline 2 & 201 & \\
\hline 3 & 348 & \\
\hline 4 & 1.876 & \\
\hline 5 & 2.115 & \\
\hline 6 & 540 & \\
\hline 7 & 814 & \\
\hline 8 & 519 & \\
\hline 9 & 1.296 & \\
\hline 10 & 2.980 & \\
\hline Total & 1184 & 7.000 .000 \\
\hline
\end{tabular}


Tabel 3. Analisa Nilai Rata-Rata Nilai Variabel Video Comments dan Followers Akun Tiktok Luna Maya

\begin{tabular}{|c|r|r|}
\hline No & Video Comments & Followers ratio \\
\hline 1 & 339 & 3.400 .000 \\
\hline 2 & 42 & \\
\hline 3 & 299 & \\
\hline 4 & 17 & \\
\hline 5 & 10 & \\
\hline 6 & 571 & \\
\hline 7 & 661 & \\
\hline 8 & 2.975 & \\
\hline 9 & 665 & \\
\hline 10 & 42 & \\
\hline Total & $\mathbf{5 6 2}$ & \\
\hline
\end{tabular}

Tabel 4. Analisa Nilai Rata-Rata Nilai Variabel Video Comments dan Followers Akun Tiktok Ayu Ting Ting

\begin{tabular}{|c|r|r|}
\hline No & Video Comments & Followers ratio \\
\hline 1 & 289 & 4.600 .000 \\
\hline 2 & 1.570 & \\
\hline 3 & 1.241 & \\
\hline 4 & 922 & \\
\hline 5 & 596 & \\
\hline 6 & 418 & \\
\hline 7 & 608 & \\
\hline 8 & 270 & \\
\hline 9 & 1.962 & $\mathbf{4 . 6 0 0 . 0 0 0}$ \\
\hline 10 & 6.007 & \\
\hline Total & \multicolumn{2}{|c|}{$\mathbf{1 3 8 8}$} \\
\hline
\end{tabular}


Tabel 5. Analisa Rata-Rata Nilai Variabel Video Comments dan Followers Akun

Tiktok Princess Syahrini

\begin{tabular}{|c|c|c|}
\hline No & Video Comments & Followers ratio \\
\hline 1 & 1.653 & 125.300 \\
\hline 2 & & \\
\hline 3 & & \\
\hline 4 & & \\
\hline 5 & & \\
\hline 6 & & \\
\hline 7 & & \\
\hline 8 & & \\
\hline 9 & & \\
\hline 10 & & \\
\hline Total & 1653 & 125.300 \\
\hline
\end{tabular}

Sumber: Pengolah Data Excel

Setelah menghitung nilai rata-rata tersebut, maka akan menemukan hasil akhir nilai rata-rata dari variabel video comments dan Followers

Tabel 6. Nilai Variabel Pada Akun Tiktok 5 Artis Indonesia dengan Tarif Endorse Termahal

\begin{tabular}{|l|r|r|r|r|r|}
\hline \multicolumn{1}{|c|}{ Variable } & Raditya Dika & Raffi Ahmad & \multicolumn{1}{c|}{$\begin{array}{c}\text { Luna } \\
\text { Maya }\end{array}$} & $\begin{array}{c}\text { Ayu Ting } \\
\text { Ting }\end{array}$ & $\begin{array}{l}\text { Princess } \\
\text { Syahrini }\end{array}$ \\
\hline $\begin{array}{l}\text { Video } \\
\text { Comments }\end{array}$ & 1637 & 1184 & 562 & 1388 & 1653 \\
\hline $\begin{array}{l}\text { Followers } \\
\text { Ratio }\end{array}$ & 754.600 & \multicolumn{3}{|c|}{ Sumber: Pengolah Data Excel } \\
\hline \multicolumn{7}{|c|}{7.000 .000} & 3.400 .000 & 4.600 .000 & 125.300 \\
\hline
\end{tabular}

Pada akun Tiktok terdapat 17 rasio yang relevan digunakan untuk mengukur kredibilitas pada masing-masing akun. Namun pada penelitian kali ini hanya berfokus untuk menghitung Video Comments to Followers Ratio. Untuk menghitung kredibilitas dari masing-masing akun Tiktok setiap Artis, peneliti menghitung dengan cara: variabel 1 akan dibagi dengan variabel 2, sehingga ditemukan hasil analisisa dari rasio tersebut. 
Tabel 7. Hasil Perhitungan Rasio Akun Tiktok

\begin{tabular}{|c|l|r|r|r|r|r|}
\hline No & \multicolumn{1}{|c|}{ Ratio } & Raditya Dika & Raffi Ahmad & Luna Maya & \multicolumn{1}{c|}{$\begin{array}{c}\text { Ayu Ting } \\
\text { Ting }\end{array}$} & $\begin{array}{c}\text { Princess } \\
\text { Syahrini }\end{array}$ \\
\hline & $\begin{array}{l}\text { Video } \\
\text { Comment } \\
\text { to }\end{array}$ & & & & & \\
& $\begin{array}{l}\text { Followers } \\
\text { Ratio }\end{array}$ & 0,002169361 & 0,000169143 & 0,000165294 & 0,000301739 & 0,013192338 \\
\hline
\end{tabular}

Sumber: Pengolah Data Excel

Video Comments to Followers Ratio memiliki karakteristik yang tinggi, artinya semakin tinggi nilai yang dihasilkan maka semakin baik kredibilitas dari performa akun tersebut. Untuk memberikan peringkat pada masing-masing Artis, peneliti memberikan angka 5 kepada Artis yang mendapatkan nilai tertinggi dan angka 1 untuk Artis yang mendapatkan nilai terendah. Berikut merupakan tabel urutan nilai yang dihasilkan oleh masing-masing akun tersebut.

\begin{tabular}{|l|c|c|c|c|c|}
\hline \multirow{2}{*}{ RATIO } & \multicolumn{5}{|c|}{ NILAI } \\
\cline { 2 - 6 } & $\begin{array}{c}\text { Raditya } \\
\text { Dika }\end{array}$ & Raffi Ahmad & $\begin{array}{c}\text { Luna } \\
\text { Maya }\end{array}$ & $\begin{array}{c}\text { Ayu Ting } \\
\text { Ting }\end{array}$ & $\begin{array}{c}\text { Princess } \\
\text { Syahrini }\end{array}$ \\
\hline $\begin{array}{l}\text { Video Comments to } \\
\text { Followers Ratio }\end{array}$ & 4 & 2 & 1 & 3 & 5 \\
\hline
\end{tabular}

Dari Tabel Nilai Rasio Akun Tiktok 5 Artis Indonesia dengan Tarif Endorse Termahal dapat simpulkan bahwa Princess Syahrini mendapatkan nilai tertinggi untuk rasio Video Comments to Followers. Sedangkan akun Tiktok Luna Maya mendapatkan nilai terendah untuk rasio ini. Jadi, pada penelitian ini Princess Syahrini memiliki kredibilitas performa yang lebih baik dibandingkan dengan Artis yang lainnya. 


\section{KESIMPULAN}

Tujuan dari penelitian ini adalah mengetahui kredibilitas performa dari akun Tiktok 5 Artis Indonesia dengan Tarif Endorse Termahal menggunakan Video Comments to Followers Ratio. 5 Artis Indonesia tersebut diantaranya: Raditya Dika, Raffi Ahmad, Luna Maya, Ayu Ting Ting, dan Princess Syahrini. Dari kelima Artis Indonesia tersebut dapat disimpulkan bahwa:

1. Peringkat pertama diraih oleh Princess Syahrini dengan nilai tertinggi yaitu 0,013192338

2. Peringkat kedua diraih oleh Raditya Dika dengan nilai 0,002169361

3. Peringkat ketiga diraih oleh Ayu Ting Ting dengan nilai 0,000301739

4. Peringkat keempat diraih oleh Raffi Ahmad dengan nilai 0,000169143

5. Peringkat kelima diraih oleh Luna Maya dengan nilai terendah yaitu 0,000165294 


\section{DAFTAR PUSTAKA}

Adawiyah, D. P. R. (2020). Pengaruh Penggunaan Aplikasi TikTok Terhadap

Kepercayaan Diri Remaja di Kabupaten Sampang. Jurnal Komunikasi, 14(2), 135-148. https://doi.org/10.21107/ilkom.v14i2.7504

Dewa, C. B., \& Safitri, L. A. (2021). Pemanfaatan Media Sosial Tiktok Sebagai

Media Promosi Industri Kuliner Di Yogyakarta Pada Masa Pandemi Covid-19 (Studi Kasus Akun TikTok Javafoodie). Khasanah Ilmu - Jurnal Pariwisata Dan Budaya, 12(1), 65-71. https://doi.org/10.31294/khi.v12i1.10132

I Putu Hendika Permana, \& Ni Putu Suci Meinarni. (2021). Ratio Analysis on Tiktok (Social Media) for Qualitative Research Using Explorative Methods. Jurnal Ekonomi \& Bisnis JAGADITHA, 8(1), 30-38. https://doi.org/10.22225/jj.8.1.2944.30-38

Ira Syafira. (2021). Inilah 5 Artis Indonesia dengan Tarif Endorse Termahal. Www.Beautynesia.Id. https://www.beautynesia.id/berita-celebrity/inilah-5artis-indonesia-dengan-tarif-endorse-termahal/b-232672

Maryam, S., Isrok'atun, I., \& Aeni, A. N. (2016). PENDEKATAN

EKSPLORATIF UNTUK MENINGKATKAN KEMAMPUAN REPRESENTASI MATEMATIS DAN KEPERCAYAAN DIRI SISWA. Jurnal Pena Ilmiah, 1(1), 551-560. https://doi.org/10.23819/PI.V1I1.2984

Prihatiningsih, W. (2017). Motif Penggunaan Media Sosial Instagram Di Kalangan Remaja. Communication, 8(1), 51. https://doi.org/10.36080/comm.v8i1.651

Rankuti, F. (2015). Buku Riset Pemasaran.

Ruth, D., \& Candraningrum, D. A. (2020). Pengaruh Motif Penggunaan Media Baru Tiktok terhadap Personal Branding Generasi Milenial di Instagram. Koneksi, 4(2), 207. https://doi.org/10.24912/kn.v4i2.8093

Tiktok.com. (2021). Tiktok. https://www.tiktok.com/

Tiktok. (n.d.). https://www.ejournal.warmadewa.ac.id/index.php/jag

Wijaya, M. (2020). Konsumsi Media Sosial Bagi Kalangan Pelajar. Jurnal Agama Sosial Dan Budaya, 3(2), 170-192. 